\title{
PENGETAHUAN KESEHATAN KESELAMATAN KERJA (K3) MAHASISWA PROGRAM STUDI PENDIDIKAN TEKNIK OTOMOTIF FAKULTAS TEKNIK UNIVERSITAS NEGERI YOGYAKARTA TERHADAP BAHAYA KECELAKAAN DI BENGKEL LAS
}

\author{
Yusfiq Harvana* \\ Fakultas Teknik, Universitas Negeri Yogyakarta \\ *Corresponding Author: harvanayusfiq@gmail.com
}

\begin{abstract}
This study aims to determine the awareness of Occupational Health and Safety (OHS) of students of the automotive engineering education study program at the UNY Faculty of Engineering against the danger of accidents in the welding workshop, which includes attitude knowledge (discipline and awareness), environmental knowledge (workshop state), equipment knowledge (equipment usage and maintenance), and health inspection knowledge. This research is a quantitative descriptive. The subjects of this study were the students of the Mechanical Engineering Education Study Program of UNY, and the research instruments consisted of 60 students. Research data collection was done by using questionnaires. The test instrument is based on the validity test with the product moment correlation formula, while the reliability test is based on the Spearman-Brown formula. The results of data analysis are presented in the form of achievement scores and then elaborated. Occupational Health Safety Knowledge (OHS) students of the automotive engineering education study program at the UNY faculty of engineering against accidents in the welding workshop, carried out with 6 knowledge measuring variables, namely: 1) students' knowledge on attitude (discipline) meets the criteria very well, with an achievement score of $81 \%$, 2) students' knowledge on attitude (awareness) has good criteria, with an achievement score of 73\%, 3) students' knowledge on the environment (workshop state) has good criteria, with a score of 73\%, 4) student knowledge on equipment (use of equipment) has good criteria, with a score of $73 \%$, and 5) student knowledge on equipment (equipment maintenance) has good criteria, with a score of $71 \%, 6)$ student knowledge on health examination has very good criteria, with a score of 83\%. Overall Occupational Health Safety Knowledge (K3) Students of the automotive engineering education study program at the UNY Faculty of Engineering against the dangers of accidents in the welding workshop have good achievement criteria, with an achievement score of $75 \%$.
\end{abstract}

Keywords: awareness, OHS, welding workshop, UNY.

\begin{abstract}
Abstrak
Penelitian ini bertujuan untuk mengetahui kesadaran Mahasiswa Program Studi Pendidikan Teknik Otomotif Fakultas Teknik UNY terhadap bahaya kecelakaan di bengkel las yang meliputi pengetahuan sikap (disiplin dan kesadaran), pengetahuan lingkungan (status bengkel), pengetahuan peralatan (penggunaan dan pemeliharaan peralatan), dan pengetahuan inspeksi kesehatan. Penelitian ini bersifat deskriptif kuantitatif. Subjek penelitian ini adalah mahasiswa Program Studi Pendidikan Teknik Mesin UNY, dan instrumen penelitian berjumlah 60 mahasiswa. Pengumpulan data penelitian dilakukan dengan menggunakan kuesioner. Instrumen tes didasarkan pada uji validitas dengan rumus korelasi product moment, sedangkan uji reliabilitas didasarkan pada rumus Spearman-Brown. Hasil analisis data disajikan dalam bentuk skor prestasi kemudian dijabarkan. Kesehatan Keselamatan Kerja (K3) mahasiswa program studi pendidikan teknik otomotif fakultas teknik UNY terhadap kecelakaan di bengkel las, dilakukan dengan 6 variabel pengukur pengetahuan, yaitu: 1) pengetahuan mahasiswa tentang sikap (disiplin) memenuhi kriteria sangat baik, dengan skor ketercapaian 81\%,2) pengetahuan siswa tentang sikap (kesadaran) memiliki kriteria baik, dengan skor ketercapaian 73\%, 3) pengetahuan
\end{abstract}




\section{Yusfiq Harvana}

siswa tentang lingkungan (workshop state) memiliki kriteria baik, dengan skor 73\%, 4) pengetahuan siswa tentang peralatan (penggunaan peralatan) memiliki kriteria baik, dengan skor 73\%, dan 5) pengetahuan siswa tentang peralatan (pemeliharaan peralatan) memiliki kriteria baik, dengan skor $71 \%$ , 6) Pengetahuan peserta didik tentang pemeriksaan kesehatan memiliki kriteria sangat baik dengan skor 83\%. Secara keseluruhan Pengetahuan Keselamatan Kesehatan Kerja (K3) Mahasiswa program studi pendidikan teknik otomotif Fakultas Teknik UNY terhadap bahaya kecelakaan di bengkel las memiliki kriteria pencapaian yang baik, dengan skor pencapaian $75 \%$.

Kata kunci: Kesadaran, K3, Bengkel las,UNY.

\section{PENDAHULUAN}

Pada era globalisasi, perusahaan sangat membutuhkan sumber daya manusia yang memiliki tingkat keahlian tertentu juga memiliki kekuatan spiritual keagamaan, pengendalian diri, kepribadian, kecerdasan, dan berakhlak mulia yang dapat dicapai melalui pendidikan. Pendidikan berperan serta membina Keselamatan Kesehatan Kerja (K3) setiap individu sehingga dapat membentuk pribadi dan akhlak mulia. Pendidikan juga yang memberikan keahlian tertentu melalui pendidikan kejuruan (Program Studi Pendidikan Teknik Otomotif) di Perguruan Tinggi kepada peserta didik (mahasiswa) untuk dapat bekerja.

Banyak cara yang dapat dilakukan untuk mencegah hal-hal yang tidak diinginkan saat praktik di bengkel, salah satu cara yang dapat dilakukan yaitu dengan mengadakan Sistem Menejemen Keselamatan Kesehatan Kerja (SMK3). Berdasarkan (PERMENAKER PER.05/MEN/1996), yang dimaksud dengan SMK3 adalah bagian dari sistem manajemen secara keseluruhan yang meliputi struktur organisasi, perencanaan, tanggung jawab, pelaksanaan, prosedur, proses, dan sumber daya yang dibutuhkan bagi pengembang, penerapan, pencapaian, pengkajian, dan pemeliharaan kebijakan keselamatan dan kesehatan kerja dalam rangka pengendalian resiko yang berkaitan dengan kegiatan kerja guna terciptanya tempat kerja yang aman, efisien, dan produktif. SMK3 tersebut meliputi penetapan kebijakan K3, perencanaan $\mathrm{K} 3$, pelaksanaan $\mathrm{K} 3$, pemantauan serta evaluasi $\mathrm{K} 3$, dan peninjauan serta peningkatan $\mathrm{K} 3$.

Universitas Negeri Yogyakarta merupakan salah satu universitas terbaik di Indonesia no. 16 klaster $2^{2}$, khususnya di Yogyakarta yang mengembangkan aktifitas pendidikan dan penelitian untuk menerapkan ilmu pengetahuan dan teknologi yang terus berkembang. Salah satu fasilitasnya adalah keberadaan laboratorium dan bengkel. Bengkel Pendidikan Teknik Otomotif terdiri dari beberapa bengkel yaitu bengkel mesin, bengkel kelistrikan, bengkel las auto bodi dan pengecatan.

Untuk mencapai Kesehatan Keselamatan Kerja (K3) yang baik diperlukan usaha yang terencana dan sistematis. Semua pihak yang berkerja didalam bengkel perlu menerapkan budaya Kesehatan Keselamatan Kerja (K3) dalam praktik sehari-hari (Nur \& Indah, 2016). Kesadaran untuk berperilaku Kesehatan Keselamatan Kerja (K3) harus ditanamkan sejak dini. 
Melalui kegiatan praktik di bengkel maupun di industri adalah salah satu sarana untuk memperkenalkan dan menanamkan kesadaran mahasiswa dalam berperilaku Kesehatan Keselamatan Kerja (K3). Mengingat dunia kerja Teknik Otomotif merupakan lingkungan kerja dengan tingkat resiko bahaya yang tinggi.

Keterlibatan secara langsung dalam dunia kerja dengan tingkat resiko bahaya yang tinggi, mengharuskan mahasiswa memiliki pengetahuan tentang Kesehatan Keselamatan Kerja (K3). Hal ini bertujuan agar mahasiswa dan semua pihak yang terlibat terhindar dari bahaya akibat kecelakaan kerja.

Penelitian ini bertujuan untuk mengetahui Bagaimana pengetahuan Kesehatan Keselamatan Kerja (K3) mahasiswa Program Studi Pendidikan Teknik Otomotif Fakultas Teknik UNY dan Seberapa besar pengetahuan mahasiswa terhadap bahaya yang muncul pada kecelakan di bengkel las.

\section{METODE}

Jenis Penelitian ini merupakan penelitian kuantitatif dengan metode pendekatan statistik deskriptif merupakan penelitian yang berfokus pada pengetahuan kesehatan keselamatan kerja (k3) mahasiswa Program Studi Pendidikan Teknik Otomotif Fakultas Teknik Universitas Negeri Yogyakarta. Objek penelitian ini adalah Bengkel las auto bodi dengan subjek penelitian mahasiswa angkatan 2018 S1 Pendidikan Teknik Otomotif Fakultas Teknik Universitas Negeri Yogyakarta. Penelitian ini memerlukan angket untuk memperoleh data mengenaipengetahuan mahasiswa terhadap bahaya kecelakaan di bengkel las. Teknik analisis data yang digunakan dalam penelitian ini adalah menggunakan deskriptif persentase.

\section{HASIL DAN PEMBAHASAN}

Hasil pendeskripsian atau penyajian data dilakukan dengan menyimpulkan data-data hasil penelitian yang berasal dari data angket pengetahuan kesehatan keselamatan kerja (k3) mahasiswa Program Studi Pendidikan Teknik Otomotif Fakultas Teknik Universitas Negeri Yogyakarta terhadap bahaya kecelakaan di bengkel las, selanjutnya data dipersentasekan, dan kemudian dikriteriakan berdasarkan indikator untuk memperoleh suatu kesimpulan. , dimana 0\% - 39\% (sangat kurang), 40\% 55\% (kurang), 56\% - 65\% (cukup), 66\% - 79\% (baik), dan 80\% - 100\% (sangat baik).

\section{Pengetahuan Mahasiswa Pada Sikap Disiplin}

Indikator pengetahuan mahasiswa pada disiplin terdiri dari 3 soal, yaitu soal nomor 1, 2, dan 3 dengan hasil skor rata-rata adalah $81 \%$ dengan kriteria sangat baik. Dalam pengaplikasiannya data hasil pengetahuan mahasiswa pada disiplin program studi pendidikan teknik otomotif fakultas teknik UNY terhadap bahaya kecelakaan di bengkel las, terbilang 


\section{Yusfiq Harvana}

sangat baik. Hal ini dikarenakan kesadaran akan disiplin Kesehatan Keselamatan Kerja (K3) sangat diperhatikan, sehingga tidak begitu berpengaruh pada rawannya kecelakaan yang terjadi saat pratikum di bengkel las. Dengan demikian, untuk mengantisipasi kecelakaan yang terjadi di bengkel las, perlu meningkatkan kesadaran akan pengetahuan disiplin Kesehatan Keselamatan Kerja (K3) sehingga dalam pelaksanaan pratikum pengelasan akan lebih nyaman dan optimal.

Secara keseluruhan, indikator di atas dapat disimpulkan dengan hasil skor rata-rata adalah $81 \%$ dengan kriteria sangat baik. Hal ini dibuktikan dengan hasil interval, dimana $80 \%-100$ $\%$ dikatakan sangat baik. Hasil data ini diperoleh dengan cara memberikan angket kepada 60 responden Mahasiswa Program Studi Pendidikan Otomotif UNY.

Pencapaian nilai skor rata-rata $81 \%$ ini sudah optimal, karena kesadaran Kesehatan Keselamatan Kerja (K3) sangat diperhatikan dan dioptimalkan terlebih pada indikator pengetahuan kedisiplinan mahasiswa saat pratikum di bengkel las. Dengan demkian, untuk mencapai hasil yang baik pada pengetahuan mahasiswa pada sikap (disiplin) program studi pendidikan teknik otomotif fakultas teknik UNY terhadap bahaya kecelakaan di bengkel las, perlu adanya arahan dan bimbingan yang baik secara optimal dari pembimbing pratikum akan pentingnya Kesehatan Keselamatan Kerja (K3).

\section{Pengetahuan Mahasiswa Pada Sikap Kepedulian}

Indikator pengetahuan mahasiswa pada kepedulian terdiri dari 2 soal, yaitu soal nomor 4 dan 5 dengan hasil skor rata-rata adalah $73 \%$ dengan kriteria baik. Pengetahuan mahasiswa pada kepedulian program studi pendidikan teknik otomotif fakultas teknik UNY terhadap bahaya kecelakaan di bengkel las, sudah baik. Hal demikian, dibuktikan dari perolehan data yang menunjukkan kriterian baik, begitu juga dalam pengaplikasiannya, dapat dilihat saat pratikum pengelasan di bengkel las, mahasiswa memiliki kepedulian Kesehatan Keselamatan Kerja (K3) dengan memakai pakaian seragam pratikum dengan benar, mengatur jarak yang pas saat pengelasan, dan memperhatikan area sekitar sebelum menghidupkan mesin las. Namun, hasil tersebut masih perlu ditingkatkan lagi, karena mengantisipasi bahaya akan kecelakaan yang terjadi sangat penting dalam pelaksanaan pratikum mahasiswa.

Secara keseluruhan, indikator di atas dapat disimpulkan dengan hasil skor rata-rata adalah $73 \%$ dengan kriteria baik. Hal ini dibuktikan dengan hasil interval, dimana $66 \%-79 \%$ dikatakan baik. Hasil data ini diperoleh dengan cara memberikan angket kepada 60 responden Mahasiswa Program Studi Pendidikan Otomotif UNY.

Pencapaian nilai skor rata-rata $73 \%$ ini sudah optimal, karena kesadaran Kesehatan Keselamatan Kerja (K3) sudah diperhatikan dan dioptimalkan terlebih pada indikator pengetahuan kedisiplinan mahasiswa saat pratikum di bengkel las. Dengan demkian, untuk 
mencapai hasil yang baik pada pengetahuan mahasiswa pada sikap (kepedulian) program studi pendidikan teknik otomotif fakultas teknik UNY terhadap bahaya kecelakaan di bengkel las, perlu adanya arahan dan bimbingan yang baik secara optimal dari pembimbing pratikum akan pentingnya Kesehatan Keselamatan Kerja (K3).

\section{Pengetahuan Mahasiswa Pada Lingkungan Keadaan Bengkel}

Variabel indikator pengetahuan mahasiswa pada lingkungan (keadaan bengkel) ini, terdiri dari 5 butir soal yaitu soal 6, 7, 8, 9, dan 10 dengan hasil skor rata-rata adalah $73 \%$ dengan kategori baik, nilai skor tertinggi ada pada soal no 6 yaitu $83 \%$ dan terendah ada pada soal no 10 yaitu $62 \%$ \% . Dengan demikian pada indikator pengetahuan mahasiswa pada lingkungan (keadaan bengkel) ini sudah optimal. Pengetahuan mahasiswa pada lingkungan (keadaan bengkel) ini perlu dipertahankan, agar sesuai dan berjalan dengan baik dalam meminimalisasi kecelakaan saat pratikum di bengkel las.

Secara keseluruhan pengetahuan mahasiswa pada lingkungan (keadaan bengkel) program studi pendidikan teknik otomotif fakultas teknik UNY terhadap bahaya kecelakaan di bengkel las, sudah baik begitu juga dalam pengaplikasiannya, mahasiswa sudah mengetahui keadaan bengkel yang baik dan yang sesuai dengan panduan Kesehatan Keselamatan Kerja (K3).

Dengan demikian, hasil pengetahuan mahasiswa pada lingkungan (keadaan bengkel) pada skor rata-rata adalah $73 \%$, yang dibuktikan dengan hasil interval, dimana $66 \%-79 \%$ dikatakan baik. Tetap perlu dioptimalkan lagi dalam pengetahuan mahasiswa terhadap lingkungan keadaan bengkel dan juga dalam pengaplikasiannya, agar dampak kecelakaan saat pratikum pengelasan dapat diantisipasi lebih baik lagi.

\section{Pengetahuan Mahasiswa Pada Pemakaian Peralatan}

Pada indikator pengetahuan mahasiswa pada pemakaian peralatan ini, terdiri dari 10 butir soal yaitu soal 11, 12, 13, 14, 15, 16, 17, 18, 19, dan 20 dengan hasil skor rata-rata adalah 73 $\%$ dengan kategori baik, nilai skor tertinggi ada pada soal no 13 yaitu $87 \%$ dan terendah ada pada soal no 17 yaitu $48 \%$. Dengan demikian indikator pengetahuan mahasiswa pada pemakaian peralatan sudah baik.

Secara keseluruhan hasil pengetahuan mahasiswa pada peralatan (pemakaian) program studi pendidikan teknik otomotif fakultas teknik UNY terhadap bahaya kecelakaan di bengkel las, sudah baik begitu juga dalam pengaplikasiannya. Hasil skor rata-rata pengetahuan mahasiswa pada peralatan (pemakaian) keseluruhan adalah $73 \%$, dengan hasil interval, dimana $66 \%-79 \%$ dikatakan baik.

Dengan demikian, hasil indikator diatas sudah optimal bagi mahasiswa pratikum di bengkel las dalam pengaplikasiannya terlebih pada pengetahuan mahasiswa akan pemakaian yang sesuai dengan standar Kesehatan Keselamatan Kerja (K3) di bengkel las. Hal tersebut 


\section{Yusfiq Harvana}

dilakukan agar membawa perbaikan pada pengetahuan mahasiswa, sehingga berdampak baik pada saat pratikum dan dapat meminimalisasi terjadinya kecelakaan.

\section{Pengetahuan Mahasiswa Pada Perawatan Peralatan}

Pada indikator pengetahuan mahasiswa pada perawatan peralatan ini, terdiri dari 5 butir soal yaitu soal 21, 22, 23, 24, dan 25 dengan hasil skor rata-rata adalah $71 \%$ dengan kategori baik, nilai skor tertinggi ada pada soal no 21 yaitu $83 \%$ dan terendah ada pada soal no 25 yaitu $52 \%$. Dengan demikian indikator pengetahuan mahasiswa pada perawatan peralatan sudah baik.

Secara keseluruhan hasil pengetahuan mahasiswa pada peralatan (perawatan) program studi pendidikan teknik otomotif fakultas teknik UNY terhadap bahaya kecelakaan di bengkel las sudah baik. Hasil skor rata-rata pengetahuan mahasiswa pada peralatan (perawatan) keseluruhan adalah $71 \%$, dengan hasil interval, dimana $66 \%$ - $79 \%$ dikatakan baik.

Dengan demikian, hasil indikator diatas sudah optimal bagi mahasiswa pratikum di bengkel las dalam pengaplikasiannya terlebih pada pengetahuan mahasiswa akan perawatan yang sesuai dengan standar Kesehatan Keselamatan Kerja (K3) di bengkel las. Hal tersebut dilakukan agar membawa perbaikan pada pengetahuan mahasiswa, sehingga berdampak baik pada saat pratikum dan dapat meminimalisasi terjadinya kecelakaan.

\section{Pengetahuan Mahasiswa Pada Pemeriksaan Kesehatan}

Variabel indikator pengetahuan mahasiswa pada pemeriksaan kesehatan ini, terdiri dari 5 butir soal yaitu soal $26,27,28,29$, dan 30 dengan hasil skor rata-rata adalah $83 \%$ dengan kategori sangat baik. Hal tersebut menjadikan hasil pengetahuan mahasiswa pada pemeriksaan kesehatan, perlu dipertahankan sesuai dengan standar Kesehatan Keselamatan Kerja (K3) yang berdampak baik dalam pelaksanaannya saat pratikum di bengkel las.

Secara keseluruhan pengetahuan mahasiswa pada pemeriksaan kesehatan program studi pendidikan teknik otomotif fakultas teknik UNY terhadap bahaya kecelakaan di bengkel las, memiliki skor rata-rata adalah $83 \%$, yang dibuktikan dengan hasil interval, dimana $80 \%$ - 100 $\%$ dikatakan sangat baik.

\section{SIMPULAN}

Berdasarkan hasil pengolahan data dan pembahasan diperoleh kesimpulan dari penelitian sebagai berikut:

1. Pengetahuan kesehatan keselamatan kerja (k3) mahasiswa Program Studi Pendidikan Teknik Otomotif Fakultas Teknik Universitas Negeri Yogyakarta terhadap bahaya kecelakaan di bengkel las berdasarkan pada pengetahuan sikap disiplin, sikap kepedulian, 
lingkungan keadaan bengkel, pemakaian peralatan, dan perawatan peralatan memperoleh kategori baik.

2. Presentase pengetahuan kesehatan keselamatan kerja (k3) mahasiswa Program Studi Pendidikan Teknik Otomotif Fakultas Teknik Universitas Negeri Yogyakarta terhadap bahaya kecelakaan di bengkel las, diperoleh presentase $75 \%$ dengan kriteria baik hal ini berdasarkan dengan kriteria presentase, dimana 66\%-79\% dikatakan kriteria baik.

Dengan demikian pengetahuan kesehatan keselamatan kerja (k3) mahasiswa Program Studi Pendidikan Teknik Otomotif Universitas Negeri Yogyakarta terhadap bahaya kecelakaan di bengkel las dalam kriteria baik.

\section{DAFTAR PUSTAKA}

ANDITA DWI HANTORO. 2015. Identifikasi Pendekatan Kaizen Di Bengkel Otomotif Fakultas Teknik Universitas Negeri Yogyakarta. E-Jurnal Pendidikan Teknik Otomotif - $S 1,9(2)$.

Bambang Triadmidi (2010) Kontribusi Pemehaman dan sikap Guru tentang K3 terhadap pelaksanaan K3 pada Pembelajaran Praktik di Bengkel Teknik Mekanik Otomotif SMK se-kota Malang. Tesis, Universitas Negeri Malang.

Daryanto. (2003). Keselamatan dan Kesehatan Kerja Bengkel. Jakarta: PT. Rineka Cipta.

Nur Hidayat dan Indah Wahyuni. 2016. Kajian Keselamatan dan Kesehatan Kerja Bengkel di Jurusan Pendidikan Teknik Sipil dan Perencanaan Fakultas teknik UNY. Jurnal Pendidikan Teknologi dan Kejuruan 23 (1).

Prilia R. Ramadan (2014) pengaruh Pengetahuan K3 dan Sikap Terhadap Kesadaran Berperilaku K3 di Lab CNC dan PLC SMK Negeri 3 Yogyakarta. Skripsi, Universitas Negeri Yogyakarta.

Ranchman, Arifin Noor. (2013) Pengaruh Praktik Kerja Industri dan Pengetahuan K3 Terhadap Kesiapan Kerja Siswa Kelas XII SMK Piri Yogyakarta. Skripsi, Universitas Negeri Yogyakarta.

Republik Indonesia. 1970. Undang-undang No. 1 Tahun 1970 tentang Keselamatan Kesehatan Kerja. Jakarta: Sekretariat Negara. 
88 Yusfiq Harvana

Jurnal Pendidikan Vokasi Otomotif, Vol 3, Nomor 1, November 2020 